\title{
PENERAPAN METODE QUALITY FUNCTION DEPLOYMENT UNTUK MENGUKUR TINGKAT KEPUASAN KONSUMEN PADA CAFE "GALILEO" TARAKAN
}

\author{
Sinawati $^{1)}$ dan Dikky Praseptian M. ${ }^{2)}$ \\ ${ }^{1,2}$ Program Studi Siste mInformasi, STMIK PPKIA Tarakanita Rahmawati \\ 1,2 Jl. Yos Sudarso No.8, Tarakan, 77111 \\ E-mail : sinawati@ppkia.ac.id ${ }^{1)}$,dikky@ppkia.ac.id ${ }^{2)}$
}

\begin{abstract}
ABSTRAK
Cafe merupakan tempat dimana pengujung dapat memesain minuman, makanan ringan dan biasanya disertai hiburanhiburan seperti musik, stand up comedy atau pentas seni lainnya. Pertumbuhan jumlah Cafe di Indonesia semakin meningkat dikarenakan keuntungan dan peluang bisnis kuliner yang memang sangat menjajikan. Namun tidak sedikit Cafe juga yang justru gulung tikar disebabkan oleh berbagai faktor. Faktor yang paling sering ditemukan yaitu Cafe terlalu monoton, tidak melakukan banyak inovasi dan perbaikan menyesuaikan bagaimana yang diinginkan konsumen. Inovasi yang biasa dilakukan suatu Cafe adalah atas hasil evaluasi pemilik Cafe itu sendiri dikarenakan masih banyak Cafe yang belum memiliki aplikasi sistem pengukuran tingkat kepuasan konsumen, sehingga hasil evaluasi yang dihasilkan bersifat subyektif bisa benar bisa salah. Konsumen adalah setiap orang pemakai barang atau jasa yang tersedia, seharusnya dari merekalah evaluasi itu didapatkan. Agar Cafe dapat memberikan pelayanan yang optimal serta dapat terus bisa bertahan menjadi pilihan konsumen. Tujuan dilakukan penelitian ini adalah agar pemilik dapat mengetahui tingkat kepuasan serta kepentingan konsumen saat ini untuk menentukan strategi perbaikannya, diawali dengan meminta konsumen untuk mengisi kuesioner yang telah disediakan dalam ruang lingkup lima dimensi yaitu tangible, realibility, responsiveness, assurance dan Empathy dimana dalam penilaian tiap atribut menggunakan 5(lima) skala likert. Metode yang digunakan yaitu Quality Function Deployment (QFD), merupakan suatu metode untuk mengetahui atribut yang mempunyai hubungan dengan parameter teknik. Parameter teknik itu sendiri adalah hasil jawaban dari keinginan konsumen untuk menentukan target yang akan dicapai, sehingga menghasilkan urutan prioritas dari parameter teknik yang perlu ditingkatkan terlebih dahulu.
\end{abstract}

Kata Kunci: Kepuasan, Konsumen, Cafe, Atribut, QFD

\section{PENDAHULUAN}

Pesatnya pertumbuhan bisnis kuliner di Indonesia salah satunya ditandai oleh jumlah café yang semakin banyak. Banyaknya café yang ada menyebabkan persaingan semakin ketat, tidak sedikit café yang gulung tikar dikarenakan tidak sanggup bertahan dengan persaingan café-café baru yang biasanya mmemiliki inovasi-inovasi terkini. Sejauh ini café untuk dapat bertahan harus melakukan invasi-inovasi yang disukai untuk memperoleh kepuasan konsumen baik dari hal menu makanan, pelayanan, suasana café dll. Penilaian yang dilakukan oleh café sering kali selalu subjektif karena belum adanya sistem yang digunakan.Kepuasan konsumen adalah tingkat perasaan konsumen setelah membandingkan antara apa yang dia terima dan harapannya. Setiap konsumen akan membandingkan antara tempat yang diharapkan dengan tempat yang diterima. Kepuasan konsumen sangat penting bagi perusahaan untuk meningkatkan bisnisnya karena dapat memberikan dampak yang positif.

Di kota Tarakan sendiri Cafe dapat mudah ditemui dan sangat banyak dijumpai di area kota dimana Cafe yang memiliki sajian khusus seperti makanan platter minuman milkshake ataupun kopi. Cafe Galileo adalah salah satu Cafe yang berada di jalan kusuma bangsa gunung lingkas Tarakan. Café ini cukup lama bertahan dalam persaingan bisnis kuliner di Kota Tarakan, walaupun sekarang posisinya mulai begeser dan tergantikan oleh café-café baru yang banyak bermunculan. Ada beberapa keluhan yang ditujukan kepada café oleh konsumen walaupun masih bersifat lisan, sehingga pemilik café kesulitan untuk memperbaiki keluhan tersebut agar kepuasan konsumen meningkat.

Kualitas pelayanan merupakan salah satu faktor penting dalam meningkatkan daya saing. Harapan dari konsumen setiap saat selalu berubah sehingga kualitas yang diberikan juga harus disesuaikan. Konsumen akan menilai kualitas suatu Cafe dengan membandingkan Cafe yang lain juga membandingkan pelayanan yang diterima dengan pelayanan yang diharapkannya. Kualitas yang baik akan memberikan dampak positif bagi setiap konsumen. Konsumen yang mengalami kepuasan dalam mendapatkan pelayanan akan berkunjung kembali ke Cafe tersebut sehingga menimbulkan loyalitas. Peningkatan kepuasan konsumen menjadi isu penting karena dapat memberikan manfaat bagi Cafe dan konsumen. Sehingga pemilik memahami dan mengetahui tingkat kepuasan serta kepentingan konsumen saat ini untuk menentukan strategi perbaikannya. Salah satu 
metode perencanaan peningkatan kualitas yang memenuhi prinsip-prinsip tersebut adalah dengan penerapan metode Quality Function Deployment (QFD). QFD merupakan metode peningkatankualitas yang berorientasi pada keinginan pelanggan (customer requirements). (Suhendar, 2015). Penerapan Metode QFD pada Café Galileo diharapkan akan sangat membantu pihak manajemen dalam menjalankan fungsifungsi kualitas pelayanan terhadap konsumen. Penelitian ini juga diharapkan dapat memberikan kerakteristik kualitas yang akan menjadi acuan bagi seluruh proses pelayanan yang dilaksanakan di café Galileo.

\section{RUANG LINGKUP}

Dalam penelitian ini permasalahan mencakup:

1. Cakupan permasalahan.

Jumlah data kuesioner atau responden yang digunakan dalam penelitian ini sebanyak 100 lembar yang diisi oleh 100 konsumen hanya pada Cafe Galileo Tarakan di tahun 2018.

2. Batasan-batasan pelnelitian.

Kriteria dimensi yang menjadi penilaian kualitas Cafe Galileo Tarakan diantaranya (Reliability) yaitu keandalan untuk memberikan pelayanan yang berkualitas, (Responsiveness) yaitu kesigapan dalam membantu konsumen dan memberikan pelayanan yang cepat dan tanggap, (Assurance) yaitu kemampuan dalam memberikan jaminan untuk menumbuhkan rasa percaya konsumen, (Empathy) yaitu rasa empati kepada konsumen dengan memberikan perhatian yang tulus dan memahami konsumen (Tangibles) yaitu penampilan fasilitas fisik. Atribut masing-masing kriteria yang telah ditentukan tingkat kepentingan dan kepuasannya menggunakan skala likert 5 tingkat yaitu, (5) Sangat puas, (4) Puas, (3) Cukup puas, (2) Kurang puas, dan (1) Sangat tidak puas.

3. Rencana hasil yang didapatkan.

Menghasilkan sebuah sistem yang dapat menganalisa pengukuran kualitas pada Cafe galileo Tarakan agar dapat membantu pemilik untuk mengetahui parameter mana yang menjadi prioritas untuk diperbaiki sehingga dapat meningkatkan kepuasan konsumen.

\section{BAHAN DAN METODE}

Ada beberapa hal yang harus disiapkan dalam penelitian ini yang pertama melakukan pengambilan sample kuesioner kepada 100 konsumen pada café galileo. Pengambilan sample kuesioner dilakukan dengan menginput data pada aplikasi yang ada pada komputer milik café galileo. Dari 100 kusioner tadi sebelumdihitung dengan metode QFD. Dilakukan uji validitas yang dimaskudkan agar instrument dapat mengukur apa yang apa yang hendak diukur, dan uji realibilitas yang dimaksud agar data yang dihasilkan benar-benar dapat dihandalkan

\subsection{Metode Quality Function Deployment}

QFD merupakan konsep yang pertama kali dikembangkan di perusahaan Misubishi Kobe Shipyard di Jepang. Istilah QFD timbul dari gagasan bahwa mutu berarti menghasilkan kepuasan pelanggan dan tugas pengembangan mutu adalah menciptakan atau menebarkan fungsi produk untuk menciptakan mutu.

Fungsi utama QFD adalah melibatkan pelanggan pada proses pengembangan produk sedini mungkin. Filosofi yang melandasinya adalah bahwa pelanggan tidak akan puas dengan produk atau jasa meskipun produk atau jasa itu telah dihasilkan dengan sempurna jika mereka memang tidak menginginkan atau membutuhkannya.

Metode QFD akan berjalan jika pelaksanan tahapan metode ini dilakukan dengan baik. Tahapan yang dilakukan pertama dalam melaksanakan metode QFD adalah penjaminan kualitas produk dan jasa, penilaian konsumen terhadap produk dan jasa, pembuatan angket kebutuhan konsumen, survei konsumen, penyusunan daftar periksa serta pembuatan matrik House Of Quality. Tahapan penerapan metode QFD tersebut terdapat pada Gambar 1.

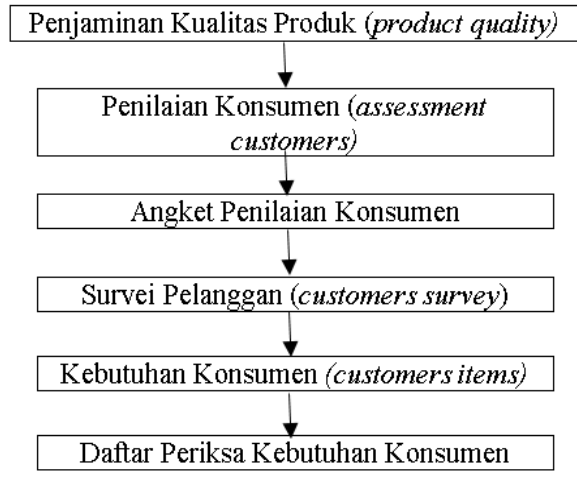

\section{Gambar 1. Tahapan Penerapan QFD}

Penggunaan Quality Function Deployment untuk mendefinisikan " apa yang dilakukan " dan progresif apa yang dilakukan terhadap " bagaimana memperbaiki " sehingga didapat hasil konsisten dalam memuaskan pelanggan.

Menurut (Palmer, 2012) survei digunakan untuk mengetahui informasi penting yang dapat berpengaruh pada usaha seseorang. Usaha tersebut jenis usaha yang baru dimulai atau usaha yang telah berjalan. Survei konsumen menjembatani kesenjangan antara konsumen dan tim pelaksana, survei dilaksanakan dengan cara bertatap muka memungkinkan keduanya dapat mengetahui hal-hal penting.

Pemilik usaha harus cermat memilih kebutuhan yang diinginkan konsumen dan bagian-bagian yang kurang disukai konsumen. Kebutuhan konsumen merupakan hasil survei penyebaran angket yang didata dalam bentuk daftar periksa atau checklist.

Daftar periksa (checklist) merupakan cara umum dalam metode penilaian kategori, daftar periksa memudahkan tim pelaksana untuk proses pada kualitas 
jasa. Menurut (Wijaya, 2011) terdapat beberapa kesulitan dalam pengisian daftar periksa kesulitan tersebut yaitu :

Skala penilaian grafik, kata-kata atau kalimat bias memiliki arti yang berbeda pada masing-masing penilai.

1. Penilai tidak bisa membedakan hasil penilaian jika daftar periksa yang diberi bobot ini digunakan.

2. Penilai tidak menerapkan bobot ini kepada faktorfaktor yang dinilai.

3. Penerapan metode QFD yang menawarkan kualitas didasarkan pada keinginan konsumen. Alur penerapan metode QFD pada dimensi penjaminan kualitas yang digunakan sesuai pendapat konsumen yang membutuhkan kualitas tersebut. Alur penerapan metode QFD dijelaskan pada Gambar 2 (Wijaya, 2018).

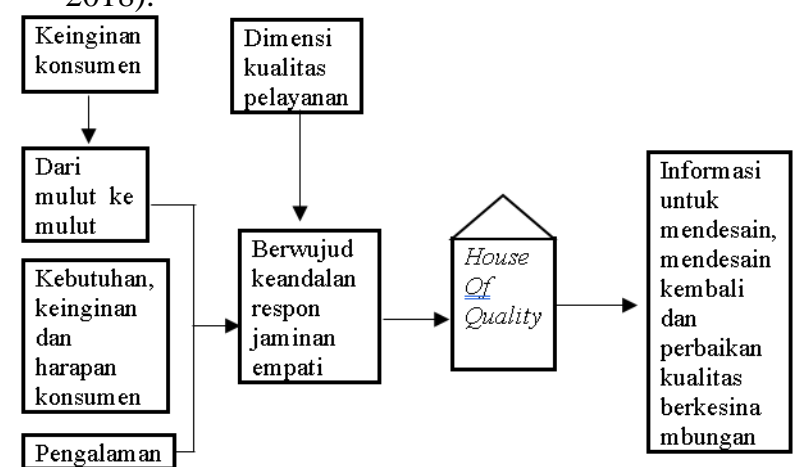

Gambar 2. Model QFD

\subsection{Analisis Uji Validitas dan Realibilitas}

Analisis adalah penguraian suatu pokok atas berbagai bagiannya dan penelaahan bagian itu sendiri serta hubungan antar bagian untuk memperoleh pengertian yang tepat dan pemahaman arti keseluruhan (Sinawati, 2018). Uji Validitas dimaskudkan agar instrument dapat mengukur apa yang apa yang hendak diukur, sedangkan uji realibilitas dimaksud agar data yang dihasilkan benarbenar dapat dihandalkan (Nawangsari, 2018).

Uji validitas dalam penelitian ini menggunakan Microsoft Excel. Uji signifikasi dilakukan dengan membandingkan nilai $r$ hitung dengan $r$ tabel untuk degree of freedom $(\mathrm{df})=\mathrm{n}-2$, dalam hal ini $\mathrm{n}$ adalah jumlah sampel $(n)=100,100-2=98$ dengan $\mathrm{df}=98$ dan alpha 0,05 didapat $\mathrm{r}$ tabel $=0,1966$. Bandingkan hasil perhitungan $r$ hitung dengan $r$ tabel, jika $r$ hitung $>r$ tabel dan nilai positif maka butir atau pertanyaan tersebut dinyatakan valid. Perbandingan hasil uji validitas apabila data yang di peroleh $\mathrm{r}$ hitung $>$ dari $\mathrm{r}$ tabel maka data tersebut dinyatakan valid yakni $\mathrm{r}$ tabel didapat 0,1966 dan $r$ hitung atribut 1 didapat 0,9605 . Hasil Perhitungan uji validitas dapat dilihat pada tabel 1 .

\section{Tabel 1. Hasil Uji Validitas}

\begin{tabular}{|c|c|c|c|}
\hline Atribut & r hitung & r tabel & Keterangan \\
\hline Atribut 1 & 0,9605 & 0,1966 & Valid \\
\hline Atribut 2 & 0,9745 & 0,1966 & Valid \\
\hline Atribut 3 & 0,9944 & 0,1966 & Valid \\
\hline Atribut 4 & 0,9927 & 0,1966 & Valid \\
\hline Atribut 5 & 0,9991 & 0,1966 & Valid \\
\hline Atribut 6 & 0,9961 & 0,1966 & Valid \\
\hline
\end{tabular}

\begin{tabular}{|c|c|c|c|}
\hline Atribut 7 & 0,9975 & 0,1966 & Valid \\
\hline Atribut 8 & 0,9912 & 0,1966 & Valid \\
\hline Atribut 9 & 0,9670 & 0,1966 & Valid \\
\hline Atribut 10 & 0,9927 & 0,1966 & Valid \\
\hline Atribut 11 & 0,9985 & 0,1966 & Valid \\
\hline Atribut 12 & 0,9943 & 0,1966 & Valid \\
\hline Atribut 13 & 0,9955 & 0,1966 & Valid \\
\hline Atribut 14 & 0,9897 & 0,1966 & Valid \\
\hline Atribut 15 & 0,9980 & 0,1966 & Valid \\
\hline Atribut 16 & 0,9923 & 0,1966 & Valid \\
\hline Atribut 17 & 0,9992 & 0,1966 & Valid \\
\hline Atribut 18 & 0,9988 & 0,1966 & Valid \\
\hline Atribut 19 & 0,9915 & 0,1966 & Valid \\
\hline Atribut 20 & 0,9955 & 0,1966 & Valid \\
\hline Atribut 21 & 0,9915 & 0,1966 & Valid \\
\hline Atribut 22 & 0,9953 & 0,1966 & Valid \\
\hline Atribut 23 & 0,9957 & 0,1966 & Valid \\
\hline Atribut 24 & 0,9919 & 0,1966 & Valid \\
\hline Atribut 25 & 0,9947 & 0,1966 & Valid \\
\hline Atribut 26 & 0,9944 & 0,1966 & Valid \\
\hline Atribut 27 & 0,9988 & 0,1966 & Valid \\
\hline Atribut 28 & 0,9997 & 0,1966 & Valid \\
\hline Atribut 29 & 0,9982 & 0,1966 & Valid \\
\hline Atribut 30 & 0,9985 & 0,1966 & Valid \\
\hline Suatu kub
\end{tabular}

Suatu kuesioner dapat dikatakan reliabel jika jawaban seseorang terhadap pernyataan adalah konsisten, pengujian reliabilitas konsumen di Microsoft Excel menggunakan rumus croanbach alpha dengan nilai > 0,60. Jika hasil uji reliabilitas $0,9964>0,60$ atau 0,60 > dari pada tabel maka dinyatakan reliabel. Apabila hasil uji reliabilitas < 0,60 dinyatakan tidak reliabel. Hasil uji realibitas seluruh atribut dapat dilihat pada tabel 2

Tabel 2. Hasil Uji Realibilitas

\begin{tabular}{|c|c|}
\hline Atribut & Varians \\
\hline Atribut 1 & 588,5 \\
\hline Atribut 2 & 314,5 \\
\hline Atribut 3 & 423,5 \\
\hline Atribut 4 & 176,0 \\
\hline Atribut 5 & 320,0 \\
\hline Atribut 6 & 285,5 \\
\hline Atribut 7 & 267,5 \\
\hline Atribut 8 & 273,5 \\
\hline Atribut 9 & 292,5 \\
\hline Atribut 10 & 186,0 \\
\hline Atribut 11 & 287,5 \\
\hline Atribut 12 & 403,0 \\
\hline Atribut 13 & 229,5 \\
\hline Atribut 14 & 366,5 \\
\hline Atribut 15 & 478,5 \\
\hline Atribut 16 & 463,5 \\
\hline Atribut 17 & 284,5 \\
\hline Atribut 18 & 349,5 \\
\hline Atribut 19 & 371,0 \\
\hline Atribut 20 & 322,5 \\
\hline Atribut 21 & 315,5 \\
\hline Atribut 22 & 356,5 \\
\hline Atribut 23 & 474,5 \\
\hline Atribut 24 & 431,0 \\
\hline Atribut 25 & 426,5 \\
\hline Atribut 26 & 350,5 \\
\hline Atribut 27 & 579,5 \\
\hline & \\
\hline & \\
\hline & \\
\hline & \\
\hline & \\
\hline & \\
\hline & \\
\hline & \\
\hline & \\
\hline & \\
\hline & \\
\hline & \\
\hline & \\
\hline & \\
\hline & \\
\hline
\end{tabular}




\begin{tabular}{|c|c|}
\hline Atribut 28 & 418,0 \\
\hline Atribut 29 & 353,0 \\
\hline Atribut 30 & 190,0 \\
\hline Jumlah Varians & 10578,5 \\
\hline Varians Total & 287091 \\
\hline Hasil Reliabilitas & 0,9964 \\
\hline Alpha & 0,60 \\
\hline Keterangan & Reliabel \\
\hline
\end{tabular}

\subsection{Bagan Alir Program}

Bagan alir program atau flowchart merupakan sebuah gambaran dalam bentuk diagram alir dari algoritma dalam suatu program, yang menyatakan arah alur program (Pahlevy 2010). Tahapan penilitian menggunakan metode QFD dapat dilihat pada gambar 3.
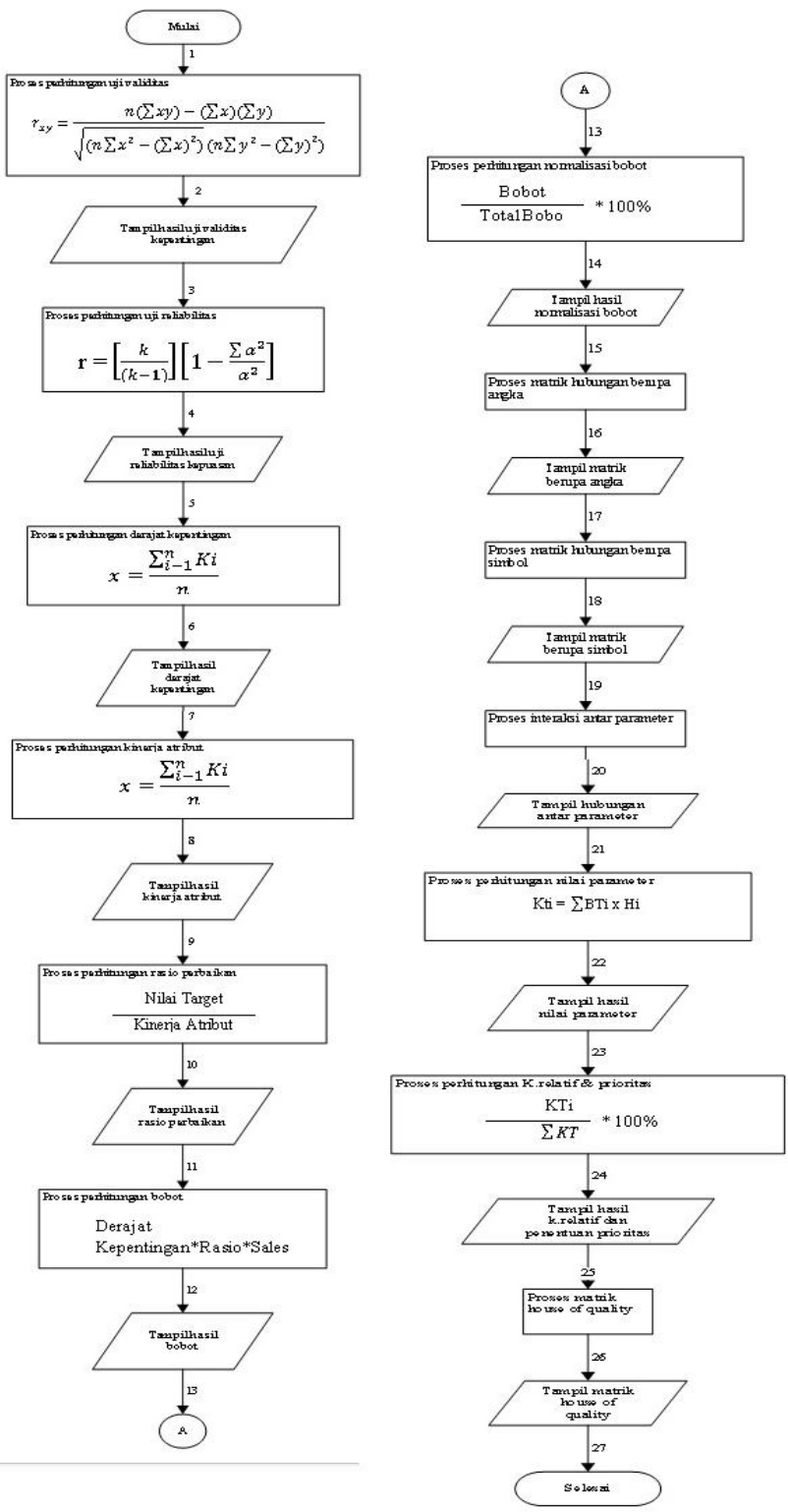

Gambar 3. Flowchart Metode QFD

\section{PEMBAHASAN}

Atribut yang menjadi penilaian pada pengisian kuesioner sebanyak 30 atribut dalam 5 dimensi seperti terlihat pada tabel 3 .

Tabel 3. Atribut Penilaian

\begin{tabular}{|c|c|c|}
\hline No & Atribut & Dimensi \\
\hline 1 & $\begin{array}{l}\text { Mampu menyajikan makanan \& } \\
\text { minuman dengan rasa yang } \\
\text { berkualitas }\end{array}$ & $\begin{array}{l}\text { Keandalan } \\
\text { (Reliability) }\end{array}$ \\
\hline 2 & $\begin{array}{l}\text { Kecepatan penyajian makanan \& } \\
\text { minuman yang dipesan }\end{array}$ & $\begin{array}{l}\text { Keandalan } \\
\text { (Reliability) }\end{array}$ \\
\hline 3 & $\begin{array}{l}\text { Keseuaian makanan \& minuman } \\
\text { yang dipesan }\end{array}$ & $\begin{array}{l}\text { Keandalan } \\
\text { (Reliability) }\end{array}$ \\
\hline 4 & $\begin{array}{l}\text { Fasilitas pendukung cukup } \\
\text { menunjang (buku, musik, dan wifi) }\end{array}$ & $\begin{array}{l}\text { Keandalan } \\
\text { (Reliability) }\end{array}$ \\
\hline 5 & $\begin{array}{l}\text { Tempat duduk yang tersedia } \\
\text { banyak dan nyaman }\end{array}$ & $\begin{array}{c}\text { Keandalan } \\
\text { (Reliability) }\end{array}$ \\
\hline 6 & $\begin{array}{l}\text { Kecepatan pelayanan dalam } \\
\text { melayani konsumen }\end{array}$ & $\begin{array}{c}\text { Kesigapan } \\
\text { (Responsiveness) }\end{array}$ \\
\hline 7 & $\begin{array}{l}\text { Sikap ramah karyawan terhadap } \\
\text { konsumen }\end{array}$ & $\begin{array}{c}\text { Kesigapan } \\
\text { (Responsiveness) } \\
\end{array}$ \\
\hline 8 & $\begin{array}{l}\text { Karyawan siap membantu } \\
\text { kesulitan dalam permintaan } \\
\text { konsumen }\end{array}$ & $\begin{array}{c}\text { Kesigapan } \\
\text { (Responsiveness) }\end{array}$ \\
\hline 9 & $\begin{array}{l}\text { Merespon permintaan konsumen } \\
\text { dengan cepat dan tepat }\end{array}$ & $\begin{array}{c}\text { Kesigapan } \\
\text { (Responsiveness) } \\
\end{array}$ \\
\hline 10 & $\begin{array}{l}\text { Memberikan informasi ketika } \\
\text { tempat duduk penuh }\end{array}$ & $\begin{array}{c}\text { Kesigapan } \\
\text { (Responsiveness) }\end{array}$ \\
\hline 11 & $\begin{array}{l}\text { Karyawan selalu semangat dalam } \\
\text { melayani permintaan konsumen }\end{array}$ & $\begin{array}{c}\text { Kesigapan } \\
\text { (Responsiveness) }\end{array}$ \\
\hline 12 & $\begin{array}{l}\text { Kebersihan penyajian makanan \& } \\
\text { minuman }\end{array}$ & $\begin{array}{c}\text { Jaminan } \\
\text { (Assurance) }\end{array}$ \\
\hline 13 & $\begin{array}{l}\text { Karyawan menumbuhkan rasa } \\
\text { nyaman terhadap konsumen } \\
\text { dengan senyum, sapa dan salam }\end{array}$ & $\begin{array}{c}\text { Jaminan } \\
\text { (Assurance) }\end{array}$ \\
\hline 14 & $\begin{array}{l}\text { Konsumen merasa nyaman pada } \\
\text { saat berada di café }\end{array}$ & $\begin{array}{c}\text { Jaminan } \\
\text { (Assurance) }\end{array}$ \\
\hline 15 & $\begin{array}{l}\text { Proses pembayaran mudah dan } \\
\text { cepat }\end{array}$ & $\begin{array}{c}\text { Jaminan } \\
\text { (Assurance) }\end{array}$ \\
\hline 16 & Harga yang disediakan terjangkau & $\begin{array}{c}\text { Jaminan } \\
\text { (Assurance) }\end{array}$ \\
\hline 17 & $\begin{array}{l}\text { Memberi jaminan penggantian } \\
\text { menu jika pesanan tidak sesuai }\end{array}$ & $\begin{array}{c}\text { Jaminan } \\
\text { (Assurance) }\end{array}$ \\
\hline 18 & $\begin{array}{l}\text { Kesabaran dalam menanggapi } \\
\text { permintaan pesanan konsumen }\end{array}$ & $\begin{array}{l}\text { Empati } \\
\text { (Empathy) }\end{array}$ \\
\hline 19 & $\begin{array}{l}\text { Karyawan segera meminta maaf } \\
\text { ketika terjadi kesalahan di dalam } \\
\text { pelayanan }\end{array}$ & $\begin{array}{l}\text { Empati } \\
\text { (Empathy) }\end{array}$ \\
\hline 20 & $\begin{array}{l}\text { Karyawan mengutamakan } \\
\text { kepentingan pelayanan konsumen }\end{array}$ & $\begin{array}{c}\text { Empati } \\
\text { (Empathy) }\end{array}$ \\
\hline 21 & $\begin{array}{l}\text { Kepekaan karyawan dalam } \\
\text { melayani keinginan konsumen }\end{array}$ & $\begin{array}{c}\text { Empati } \\
\text { (Empathy) }\end{array}$ \\
\hline 22 & $\begin{array}{l}\text { Komunikasi yang baik antara } \\
\text { karyawan dengan konsumen dalam } \\
\text { pelayanan }\end{array}$ & $\begin{array}{c}\text { Empati } \\
\text { (Empathy) }\end{array}$ \\
\hline 23 & Kebersihan dalam ruangan café & $\begin{array}{l}\text { Bukti Fisik } \\
\text { (Tangibles) }\end{array}$ \\
\hline 24 & Keindahan pada interior café & $\begin{array}{l}\text { Bukti Fisik } \\
\text { (Tangibles) }\end{array}$ \\
\hline 25 & Pencahayaan yang nyaman & $\begin{array}{l}\text { Bukti Fisik } \\
\text { (Tangibles) }\end{array}$ \\
\hline 26 & Sirkulasi udara yang nyaman & Bukti Fisik \\
\hline
\end{tabular}




\begin{tabular}{|c|l|c|}
\hline 27 & $\begin{array}{l}\text { Kerapian dan kebersihan } \\
\text { penampilan karyawan }\end{array}$ & $\begin{array}{l}\text { Bukti Fisik } \\
\text { (Tangibles) }\end{array}$ \\
\hline 28 & Peralatan penyajian yang layak & $\begin{array}{l}\text { Bukti Fisik } \\
\text { (Tangibles) }\end{array}$ \\
\hline 29 & Lokasi café yang strategis & $\begin{array}{l}\text { Bukti Fisik } \\
\text { (Tangibles) }\end{array}$ \\
\hline 30 & $\begin{array}{l}\text { Menyediakan lahan parkir yang } \\
\text { luas }\end{array}$ & $\begin{array}{l}\text { Bukti Fisik } \\
\text { (Tangibles) }\end{array}$ \\
\hline
\end{tabular}

Dari 30 atribut tadi konsumen mengisi dengan skala 1-5 dan 2 jenis penilaian yaitu kepuasan dan kepentingan. Berikut hasil rekap kuesioner kepentingan pada tabel 4 serta rekap kuesioner kepuasan pada tabel 5.

Tabel 4. Rekap Kuesioner Kepentingan

\begin{tabular}{|c|c|c|c|c|c|}
\hline \multirow[b]{2}{*}{ Atribut } & \multicolumn{5}{|c|}{ Skala } \\
\hline & 1 & 2 & 3 & 4 & 5 \\
\hline 1 & 50 & 35 & 15 & 0 & 0 \\
\hline 2 & 52 & 31 & 16 & 1 & 0 \\
\hline 3 & 60 & 29 & 11 & 0 & 0 \\
\hline 4 & 62 & 20 & 16 & 2 & 0 \\
\hline 5 & 65 & 22 & 11 & 2 & 0 \\
\hline 6 & 60 & 27 & 12 & 1 & 0 \\
\hline 7 & 67 & 27 & 5 & 0 & 1 \\
\hline 8 & 59 & 31 & 9 & 1 & 0 \\
\hline 9 & 55 & 38 & 6 & 1 & 0 \\
\hline 10 & 58 & 29 & 11 & 2 & 0 \\
\hline 11 & 63 & 27 & 9 & 1 & 0 \\
\hline 12 & 74 & 19 & 7 & 0 & 0 \\
\hline 13 & 72 & 19 & 8 & 1 & 0 \\
\hline 14 & 77 & 17 & 6 & 0 & 0 \\
\hline 15 & 70 & 25 & 5 & 0 & 0 \\
\hline 16 & 76 & 19 & 5 & 0 & 0 \\
\hline 17 & 63 & 24 & 11 & 2 & 0 \\
\hline 18 & 69 & 25 & 6 & 0 & 0 \\
\hline 19 & 72 & 19 & 8 & 1 & 0 \\
\hline 20 & 75 & 17 & 8 & 0 & 0 \\
\hline 21 & 62 & 22 & 15 & 1 & 0 \\
\hline 22 & 66 & 20 & 14 & 0 & 0 \\
\hline 23 & 74 & 17 & 8 & 1 & 0 \\
\hline 24 & 73 & 19 & 7 & 1 & 0 \\
\hline 25 & 72 & 18 & 9 & 1 & 0 \\
\hline 26 & 70 & 23 & 7 & 0 & 0 \\
\hline 27 & 62 & 32 & 6 & 0 & 0 \\
\hline 28 & 68 & 24 & 8 & 0 & 0 \\
\hline 29 & 68 & 23 & 6 & 3 & 0 \\
\hline 30 & 64 & 26 & 7 & 3 & 0 \\
\hline
\end{tabular}

Tabel 5. Rekap Kuesioner Kepuasan

\begin{tabular}{|c|c|c|c|c|c|}
\hline \multirow{2}{*}{ Atribut } & \multicolumn{5}{|c|}{ Skala } \\
\cline { 2 - 6 } & $\mathbf{1}$ & $\mathbf{2}$ & $\mathbf{3}$ & $\mathbf{4}$ & $\mathbf{5}$ \\
\hline 1 & 26 & 59 & 14 & 1 & 0 \\
\hline 2 & 22 & 45 & 27 & 4 & 2 \\
\hline 3 & 30 & 50 & 17 & 2 & 1 \\
\hline 4 & 25 & 33 & 30 & 9 & 3 \\
\hline 5 & 23 & 39 & 35 & 2 & 1 \\
\hline 6 & 26 & 40 & 29 & 5 & 0 \\
\hline 7 & 36 & 36 & 21 & 6 & 1 \\
\hline 8 & 31 & 39 & 24 & 6 & 0 \\
\hline 9 & 29 & 42 & 23 & 6 & 0 \\
\hline 10 & 26 & 32 & 30 & 12 & 0 \\
\hline 11 & 24 & 42 & 28 & 5 & 1 \\
\hline
\end{tabular}

\begin{tabular}{|l|l|l|l|l|l|}
\hline 12 & 36 & 45 & 17 & 1 & 1 \\
\hline 13 & 28 & 38 & 25 & 8 & 1 \\
\hline 14 & 39 & 37 & 24 & 0 & 0 \\
\hline 15 & 45 & 42 & 11 & 2 & 0 \\
\hline 16 & 45 & 41 & 12 & 2 & 0 \\
\hline 17 & 28 & 40 & 27 & 5 & 0 \\
\hline 18 & 27 & 44 & 27 & 2 & 0 \\
\hline 19 & 27 & 48 & 21 & 3 & 1 \\
\hline 20 & 34 & 40 & 23 & 2 & 1 \\
\hline 21 & 24 & 39 & 34 & 3 & 0 \\
\hline 22 & 25 & 46 & 26 & 3 & 0 \\
\hline 23 & 35 & 50 & 13 & 2 & 0 \\
\hline 24 & 37 & 47 & 11 & 5 & 0 \\
\hline 25 & 43 & 40 & 16 & 1 & 0 \\
\hline 26 & 33 & 44 & 19 & 4 & 0 \\
\hline 27 & 28 & 58 & 13 & 1 & 0 \\
\hline 28 & 34 & 46 & 20 & 0 & 0 \\
\hline 29 & 39 & 39 & 19 & 3 & 0 \\
\hline 30 & 22 & 39 & 25 & 11 & 3 \\
\hline
\end{tabular}

Selanjutnya menghitung derajat kepentingan dengan cara rekap jawaban per skala dikalikan nilai skala kriteria di bagi jumlah responden msaing masing atribut. Berikut hasilnya terlihat pada tabel 6 .

Tabel 6. Derajat Kepentingan

\begin{tabular}{|c|c|c|}
\hline Atribut & $\begin{array}{c}\text { Jumlah } \\
\text { Pertanyaan }\end{array}$ & $\begin{array}{c}\text { Derajat } \\
\text { Kepentingan }\end{array}$ \\
\hline 1 & 435 & 4,35 \\
\hline 2 & 434 & 4,34 \\
\hline 3 & 449 & 4,49 \\
\hline 4 & 442 & 4,42 \\
\hline 5 & 450 & 4,5 \\
\hline 6 & 446 & 4,46 \\
\hline 7 & 459 & 4,59 \\
\hline 8 & 448 & 4,48 \\
\hline 9 & 447 & 4,47 \\
\hline 10 & 443 & 4,43 \\
\hline 11 & 452 & 4,52 \\
\hline 12 & 467 & 4,67 \\
\hline 13 & 462 & 4,62 \\
\hline 14 & 471 & 4,71 \\
\hline 15 & 465 & 4,65 \\
\hline 16 & 471 & 4,71 \\
\hline 17 & 448 & 4,48 \\
\hline 18 & 463 & 4,63 \\
\hline 19 & 462 & 4,62 \\
\hline 20 & 467 & 4,67 \\
\hline 21 & 445 & 4,45 \\
\hline 22 & 452 & 4,52 \\
\hline 23 & 464 & 4,64 \\
\hline 24 & 464 & 4,64 \\
\hline 25 & 461 & 4,61 \\
\hline 26 & 463 & 4,63 \\
\hline 27 & 456 & 4,56 \\
\hline 28 & 460 & 4,6 \\
\hline 29 & 456 & 4,56 \\
\hline 30 & 451 & 4,51 \\
\hline
\end{tabular}

Langkah selanjutnya mencari nilai kinerja atribut, sama dengan derajat kepentingan, kinerja atribut diperoleh dari kuesioner kepuasan. Setelah itu menentukan nilai target yang diperoleh dari target yang 
diinginkan oleh pemilik café untuk masing -masing atribut. Rasio perbaikan diperoleh dari nilai target di bagi dengan atribut. Dapat dilihat pada tabel 7.

Tabel 7. Rasio Perbaikan

\begin{tabular}{|c|c|c|c|}
\hline Atribut & $\begin{array}{c}\text { Nilai } \\
\text { Target }\end{array}$ & $\begin{array}{l}\text { Kinerja } \\
\text { Atribut }\end{array}$ & $\begin{array}{c}\text { Rasio } \\
\text { Perbaikan } \\
\end{array}$ \\
\hline 1 & 5 & 4,1 & 1,2195 \\
\hline 2 & 5 & 3,81 & 1,3123 \\
\hline 3 & 5 & 4,06 & 1,2315 \\
\hline 4 & 5 & 3,68 & 1,3587 \\
\hline 5 & 5 & 3,81 & 1,3123 \\
\hline 6 & 5 & 3,87 & 1,2920 \\
\hline 7 & 5 & 4 & 1,2500 \\
\hline 8 & 4 & 3,95 & 1,0127 \\
\hline 9 & 4 & 3,94 & 1,0152 \\
\hline 10 & 5 & 3,72 & 1,3441 \\
\hline 11 & 4 & 3,83 & 1,0444 \\
\hline 12 & 5 & 4,14 & 1,2077 \\
\hline 13 & 5 & 3,84 & 1,3021 \\
\hline 14 & 5 & 4,15 & 1,2048 \\
\hline 15 & 4 & 4,3 & 0,9302 \\
\hline 16 & 5 & 4,29 & 1,1655 \\
\hline 17 & 5 & 3,91 & 1,2788 \\
\hline 18 & 5 & 3,96 & 1,2626 \\
\hline 19 & 4 & 3,97 & 1,0076 \\
\hline 20 & 4 & 4,04 & 0,9901 \\
\hline 21 & 5 & 3,84 & 1,3021 \\
\hline 22 & 5 & 3,93 & 1,2723 \\
\hline 23 & 4 & 4,18 & 0,9569 \\
\hline 24 & 4 & 4,16 & 0,9615 \\
\hline 25 & 5 & 4,25 & 1,1765 \\
\hline 26 & 4 & 4,06 & 0,9852 \\
\hline 27 & 4 & 4,13 & 0,9685 \\
\hline 28 & 5 & 4,14 & 1,2077 \\
\hline 29 & 4 & 4,14 & 0,9662 \\
\hline 30 & 5 & 3,66 & 1,3661 \\
\hline
\end{tabular}

Selanjutnya menetukan sales point, sama halnya dengan nilai target, sales point ditentukan oleh pemilik café. Bobot di dapatkan dengan mengalikan derajat kepentingan, rasio perbaikan dan sales point. Normalisasi bobot di dapat dari bobot dibagi dengan jumlah bobot seluruh atribut. Hasilnya dapat terlihat pada tabel 8 .

Tabel 8. Bobot \& Normalisasi Bobot

\begin{tabular}{|l|c|c|c|c|c|}
\hline Atribut & Derajat & Rasio & $\begin{array}{c}\text { Sales } \\
\text { Point }\end{array}$ & Bobot & $\begin{array}{c}\text { Normalisasi } \\
\text { Bobot }\end{array}$ \\
\hline 1 & 4,35 & 1,2195 & 1,5 & 7,9573 & 0,0357 \\
\hline 2 & 4,34 & 1,3123 & 1,5 & 8,5433 & 0,0383 \\
\hline 3 & 4,49 & 1,2315 & 1,5 & 8,2943 & 0,0372 \\
\hline 4 & 4,42 & 1,3587 & 1,5 & 9,0082 & 0,0404 \\
\hline 5 & 4,5 & 1,3123 & 1,5 & 8,8583 & 0,0397 \\
\hline 6 & 4,46 & 1,2920 & 1,5 & 8,6434 & 0,0387 \\
\hline
\end{tabular}

\begin{tabular}{|l|c|c|c|c|c|}
\hline 7 & 4,59 & 1,2500 & 1,5 & 8,6063 & 0,0386 \\
\hline 8 & 4,48 & 1,0127 & 1,2 & 5,4441 & 0,0244 \\
\hline 9 & 4,47 & 1,0152 & 1,2 & 5,4457 & 0,0244 \\
\hline 10 & 4,43 & 1,3441 & 1,5 & 8,9315 & 0,0400 \\
\hline 11 & 4,52 & 1,0444 & 1,2 & 5,6648 & 0,0254 \\
\hline 12 & 4,67 & 1,2077 & 1,5 & 8,4601 & 0,0379 \\
\hline 13 & 4,62 & 1,3021 & 1,5 & 9,0234 & 0,0404 \\
\hline 14 & 4,71 & 1,2048 & 1,5 & 8,5120 & 0,0382 \\
\hline 15 & 4,65 & 0,9302 & 1,2 & 5,1907 & 0,0233 \\
\hline 16 & 4,71 & 1,1655 & 1,5 & 8,2343 & 0,0369 \\
\hline 17 & 4,48 & 1,2788 & 1,5 & 8,5934 & 0,0385 \\
\hline 18 & 4,63 & 1,2626 & 1,5 & 8,7689 & 0,0393 \\
\hline 19 & 4,62 & 1,0076 & 1,2 & 5,5859 & 0,0250 \\
\hline 20 & 4,67 & 0,9901 & 1,2 & 5,5485 & 0,0249 \\
\hline 21 & 4,45 & 1,3021 & 1,5 & 8,6914 & 0,0390 \\
\hline 22 & 4,52 & 1,2723 & 1,5 & 8,6260 & 0,0387 \\
\hline 23 & 4,64 & 0,9569 & 1,2 & 5,3282 & 0,0239 \\
\hline 24 & 4,64 & 0,9615 & 1,2 & 5,3538 & 0,0240 \\
\hline 25 & 4,61 & 1,1765 & 1,5 & 8,1353 & 0,0365 \\
\hline 26 & 4,63 & 0,9852 & 1,2 & 5,4739 & 0,0245 \\
\hline 27 & 4,56 & 0,9685 & 1,2 & 5,2998 & 0,0238 \\
\hline 28 & 4,6 & 1,2077 & 1,5 & 8,3333 & 0,0374 \\
\hline 29 & 4,56 & 0,9662 & 1,2 & 5,2870 & 0,0237 \\
\hline 30 & 4,51 & 1,3661 & 1,5 & 9,2418 & 0,0414 \\
\hline
\end{tabular}

Langkah kesepuluh menentukan parameter teknik yang merupakan hasil penerjemah dari keinginan konsumen, dari keinginan konsumen diterjemahkan kedalam bahasa teknik yang dapat diukur untuk menentukan target yang akan dicapai dan untuk menentukan atribut mana yang nantinya akan dikembangkan. Adapun hasil penerjemah dari keinginan dan kebutuhan konsumen dapat diperoleh parameter teknik dilihat pada tabel 9 .

Tabel 9. Parameter Teknik

\begin{tabular}{|c|l|}
\hline No & \multicolumn{1}{|c|}{ Paramater Teknik } \\
\hline 1 & $\begin{array}{l}\text { Meningkatkan kualitas penyajian dan pelayanan } \\
\text { terhadap konsumen }\end{array}$ \\
\hline 2 & Meningkatkan kecepatan pelayanan dalam penyajian \\
\hline 3 & Menyesuaikan pesanan konsumen \\
\hline 4 & Penambahan fasilitas café \\
\hline 5 & $\begin{array}{l}\text { Memberikan jaminan ketika terjadi kesalahan } \\
\text { pelayanan }\end{array}$ \\
\hline 6 & $\begin{array}{l}\text { Memberikan pengembangan softskill dan sistem } \\
\text { pelayanan prima kepada karyawan }\end{array}$ \\
\hline 7 & Meningkatkan kebersihan \\
\hline 8 & Menyederhanakan proses pembayaran \\
\hline 9 & $\begin{array}{l}\text { Menyediakan menu makanan dan minuman dengan } \\
\text { harga yang sesuai }\end{array}$ \\
\hline 10 & Menumbuhkan rasa empati kepada konsumen \\
\hline 11 & Kualitas udara dan pencahayaan yang baik \\
\hline 12 & Kerapian dan kebersihan dalam berpakaian \\
\hline 13 & Meningkatkan peralatan penyajian \\
\hline 14 & Mempersiapkan lokasi yang mudah ditemukan \\
\hline 15 & Menyediakan lahan parkir yang luas \\
\hline \multicolumn{2}{|c|}{ Langkah selanjutnya menentukan interaksi antara } \\
\hline
\end{tabular}
keinginan konsumen dengan parameter teknik. Matrik interaksi adalah untuk menghubungkan antara atribut yang dianggap penting oleh konsumen dengan parameter teknik yang telah disusun. Lemah dan kuatnya interaksi yang terjadi dipengaruhi oleh tingkat kedekatan antara atribut dengan parameter teknik, interaksi yang terjadi kemudian dinyatakan dalam angka dan simbol. Berikut angka dan simbol pda tabel 10 . 
Tabel 10. Hubungan Antar Parameter Teknik

\begin{tabular}{|c|l|}
\hline Simbol & \multicolumn{1}{|c|}{ Angka } \\
\hline & Tingkat hubungan kuat dengan nilai 9 \\
\hline & Tingkat hubungan sedang dengan nilai 3 \\
\hline & Tingkat hubungan lemah dengan nilai 1 \\
\hline
\end{tabular}

Kemudian nilai normalisasi bobot masing-masing atribut yang memiliki hubungan dengan paramater teknik dikalikan dengan nilai hubungannya. Hasilnya dapat dilihat pada tabel 11.

Tabel 11. Nilai Parameter Teknik

\begin{tabular}{|c|l|c|}
\hline No. & \multicolumn{1}{|c|}{ Paramater Teknik } & Nilai \\
\hline 1 & $\begin{array}{l}\text { Meningkatkan kualitas penajian dan } \\
\text { pelayanan terhadap konsumen }\end{array}$ & 0,5766 \\
\hline 2 & $\begin{array}{l}\text { Meningkatkan kecepatan pelayanan dalam } \\
\text { penyajian }\end{array}$ & 0,6934 \\
\hline 3 & Menyesuaikan pesanan konsumen & 0,4502 \\
\hline 4 & Penambahan fasilitas café & 1,3167 \\
\hline 5 & $\begin{array}{l}\text { Memberikan jaminan ketika terjadi } \\
\text { kesalahan pelayanan }\end{array}$ & 0,3839 \\
\hline 6 & $\begin{array}{l}\text { Memberikan pengembangan softskill dan } \\
\text { sistem pelayanan prima kepada karyawan }\end{array}$ & 1,8424 \\
\hline 7 & Meningkatkan kebersihan & 0,7403 \\
\hline 8 & Menyederhanakan proses pembayaran & 0,2094 \\
\hline 9 & $\begin{array}{l}\text { Menyediakan menu makanan dan } \\
\text { minuman dengan harga yang sesuai }\end{array}$ & 0,3322 \\
\hline 10 & $\begin{array}{l}\text { Menumbuhkan rasa empati kepada } \\
\text { konsumen }\end{array}$ & 1,1022 \\
\hline 11 & Kualitas udara dan pencahayaan yang baik & 0,6635 \\
\hline 12 & Kerapian dan kebersihan dalam berpakaian & 0,2138 \\
\hline 13 & Meningkatkan peralatan penyajian & 0,3741 \\
\hline 14 & $\begin{array}{l}\text { Mempersiapkan lokasi yang mudah } \\
\text { ditemukan }\end{array}$ & 0,3376 \\
\hline 15 & Menyediakan lahan parkir yang luas & 0,3728 \\
\hline & \multicolumn{2}{|c|}{ Total } \\
\hline
\end{tabular}

Untuk menentukan prioritas parameter teknik diperoleh dari hasil bagi antara masing-masing parameter teknik absolut dengan jumlah total dari parameter teknik absolut dikalikan $100 \%$. Sehingga nilai yang dihasilkan dari perhitungan ini digunakan sebagai urutan prioritas agar mengetahui parameter mana yang diprioritaskan terlebih dahulu dalam meningkatkan kualitas. Hasilnya dpat dilihat pada tabel 12

Tabel 12. Prioritas Parameter Teknik

\begin{tabular}{|c|l|c|c|}
\hline No & \multicolumn{1}{|c|}{ Parameter Teknik } & $\begin{array}{c}\text { Kepentingan } \\
\text { Relatif }\end{array}$ & Prioritas \\
\hline 1 & $\begin{array}{l}\text { Meningkatkan kualitas } \\
\text { penyajian dan pelayanan } \\
\text { terhadap konsumen }\end{array}$ & 0,0600 & 7 \\
\hline 2 & $\begin{array}{l}\text { Meningkatkan kecepatan } \\
\text { pelayanan dalam } \\
\text { penyajian }\end{array}$ & 0,0722 & 5 \\
\hline 3 & $\begin{array}{l}\text { Menyesuaikan pesanan } \\
\text { konsumen }\end{array}$ & 0,0468 & 8 \\
\hline 4 & $\begin{array}{l}\text { Penambahan fasilitas } \\
\text { café }\end{array}$ & 0,1370 & 2 \\
\hline
\end{tabular}

\begin{tabular}{|c|c|c|c|}
\hline 5 & $\begin{array}{l}\text { Memberikan jaminan } \\
\text { ketika terjadi kesalahan } \\
\text { pelayanan }\end{array}$ & 0,0399 & 9 \\
\hline 6 & $\begin{array}{l}\text { Memberikan } \\
\text { pengembangan softskill } \\
\text { dan sistem pelayanan } \\
\text { prima kepada karyawan }\end{array}$ & 0,1917 & 1 \\
\hline 7 & $\begin{array}{l}\text { Meningkatkan } \\
\text { kebersihan }\end{array}$ & 0,0770 & 4 \\
\hline 8 & $\begin{array}{l}\text { Menyederhanakan } \\
\text { proses pembayaran }\end{array}$ & 0,0218 & 15 \\
\hline 9 & $\begin{array}{l}\text { Menyediakan menu } \\
\text { makanan dan minuman } \\
\text { dengan harga yang } \\
\text { sesuai }\end{array}$ & 0,0346 & 13 \\
\hline 10 & $\begin{array}{l}\text { Menumbuhkan rasa } \\
\text { empati kepada } \\
\text { konsumen }\end{array}$ & 0,1147 & 3 \\
\hline 11 & $\begin{array}{l}\text { Kualitas udara dan } \\
\text { pencahayaan yang baik }\end{array}$ & 0,0691 & 6 \\
\hline 12 & $\begin{array}{l}\text { Kerapian dan kebersihan } \\
\text { dalam berpakaian }\end{array}$ & 0,0223 & 14 \\
\hline 13 & $\begin{array}{l}\text { Meningkatkan peralatan } \\
\text { penyajian }\end{array}$ & 0,0389 & 10 \\
\hline 14 & $\begin{array}{l}\text { Mempersiapkan lokasi } \\
\text { yang mudah ditemukan }\end{array}$ & 0,0351 & 12 \\
\hline 15 & $\begin{array}{l}\text { Menyediakan lahan } \\
\text { parkir yang luas }\end{array}$ & 0,0388 & 11 \\
\hline
\end{tabular}

\section{KESIMPULAN}

Pengukuran kepuasan konsumen pada Cafe Galileo Tarakan menggunakan metode Quality Function Deployment, secara umum menghasilkan nilai parameter teknik yang baik karena jauh dari angka 1, namun jika harus ada yang diperbaki maka menghasilkan 3 prioritas parameter yang harus di perbaiki terlebih dahulu yaitu Memberikan pengembangan softskill dan sistem pelayanan prima kepada karyawan, Penambahan fasilitas café dan Menumbuhkan rasa empati kepada karyawan.

\section{SARAN}

Bagi pihak Café Galileo Tarakan diharapkan menggunakan aplikasi ini sebagai bahas evaluasi. Kedepannya dikembangkan lagi sistem ini dalam proses pengisian kuesioner secara online serta diharapkan mencoba membandingkan dengan metode pengukuran kupuasan lainnya.

\section{DAFTAR PUSTAKA}

Nawangsari, Sri \& Widiastuti, Retno 2018, Analisis Pengaruh Kualitas Layanan, Kepercayaan dan Layanan Mobile Banking Terhadap Kepuasan Nasabah Bank (Studi Kasus Pada PT Bank DKIDepok), Jurnal Sebatik, 51-55.

Pahlevy 2010, Pengertian Flowchart dan definisi data, diakses tanggal 10 Januari 2019, http://www.sumberpengertian.co/pengertianflowchart-menurut-para-ahli-lengkap. 
Praseptian M., Dikky \& Indriani, Aida 2014, Implementasi Text Mining dalam Klasifikasi Buku dengan Metode Naïve Bayes Classifier Studi Kasus Pada Perpustakaan STMIK PPKIA Tarakanita Rahmawati. Seminar Nasional Inovasi \& Tren (SNIT), 243-247.

Sinawati \& Praseptian M., Dikky 2018. Analisis Sentimen pada Angket Kualitas Pengajaran Semester Bagi Keberhasilan Dosen. Seminar
Nasional Teknologi dan Informatika (SNATIF), 357-343.

Suhendar, Endang \& Suroto 2015, Penerapan Metode Quality Function Deployment (QFD) dalam Upaya Peningkatan Kualitas Pelayanan Akademik pada UB. Jurnal Factor Exacta, 372-277.

Wijaya, Tony 2018, Manajemen Kualitas Jasa (Edisi Kedua), Indeks, Jakarta. 